\title{
Feasibility of Low-Cost Seed Potato Storage in Kenya: The Case of Diffused Light Storage in Nyandarua County
}

\author{
Jane Muthoni ${ }^{1}$, J. N. Kabira ${ }^{1}$, D. Kipkoech ${ }^{1}$, G. O. Abong ${ }^{2} \&$ J. H. Nderitu ${ }^{3}$ \\ ${ }^{1}$ Kari Agricultural Research Institute (KARI), National Potato Research Centre -Tigoni, Limuru, Kenya \\ ${ }^{2}$ Department of Food Science, Nutrition and Technology, University of Nairobi, Kenya \\ ${ }^{3}$ Mount Kenya University, Kenya \\ Correspondence: Jane Muthoni, KARI-National Potato Research Centre-Tigoni, Limuru, Kenya. E-mail: \\ jayney480@yahoo.com, janemuthoni1974@gmail.com
}

Received: August 30, 2013 Accepted: November 25, 2013 Online Published: December 15, 2013

doi:10.5539/jas.v6n1p59 URL: http://dx.doi.org/10.5539/jas.v6n1p59

\begin{abstract}
An on-farm storage trial was conducted at six sites in Nyandarua County using seed tubers of eight officially recognized Kenyan potato varieties and one commonly grown farmers' variety called Cangi. The seeds were stored under diffuse light store (DLS) conditions in low-cost structures owned by the growers to test the feasibility of prolonged seed storage under on-farm conditions. Three farmers' groups and three individual farmers were used in this study. In general, DLS wooden structures with iron sheet roof or mud-walled with iron sheet roofs were used for storage.

Most of the varieties stored satisfactorily for up to 8 months. Kenya Mpya and Kenya Mavuno had higher overall acceptability than Sherekea, Asante, Desiree, Kenya Karibu, Tigoni and Dutch Robjin. Kenya Mpya, Sherekea and Kenya Mavuno had the least shrinkage following 8 months of storage. The unofficial cultivar Cangi which is the most popular in Nyandarua had poor storability but could be planted 2 to 3 months following harvest. Results indicated that DLS could be used by ware potato growers for prolonged seed storage the following season. This way the growers could be assured of good potato harvests due to the use of well sprouted tubers. This is critical in case of seasons with low or less than average rainfall as experienced in recent years.
\end{abstract}

Keywords: diffuse light store, potato storage

\section{Introduction}

The potato (Solanum tuberosum $L$ ) is an important food and income security crop in Kenya being second to maize in production and utilization. This crop is grown in most highlands (1800-3000 $\mathrm{m}$ above sea level) wherever maize performs poorly. Availability of good quality seed is a major constraint to increased ware potato production to meet the food demands of increasing rural and urban populations besides processing requirements. In order to improve the quality of farm-saved seeds, farmers are usually encouraged by extension workers and researchers to conduct positive seed selection (MoA, 2008). If such "clean seeds" are well-sprouted before planting, the on-farm yields can be improved substantially when complemented with adequate agronomic practices (Kabira et al., 2006; Kinyua et al., 2012; Nyongesa et al., 2012).

In production areas adjacent to the Aberdares selected for this study, the rains have dwindled in certain years compared with their levels in the 1980s. Changed weather patterns with erratic rainfall patterns have negatively affected potato productivity, particularly when unsprouted or even poorly sprouted seed is used by farmers for planting. Well-sprouted seed which leads to early crop establishment and consequently higher yields can be obtained through simple and low-cost technologies such as diffused light storage (Kabira et al., 2006). Individual farmers and farmers' groups cannot afford refrigerated storage however attractive it is for prolonged seed storage. The later system is currently used for storage of basic seeds at KARI-Tigoni and for certified seeds at Agricultural Development Corporation (ADC), Molo (Kaguongo et al., 2010).

Although Nyandarua is one of the largest potato producing counties in Kenya, the average yieldshave remained at less than $10 \mathrm{t} / \mathrm{ha}$ compared to on-station figures of 30-60 t/ha. Many farmers store their seed potato tubers in dark stores instead of using better techniques such as diffused light stores (Kinyae et al., 1996; Kipkoech et al., 2012). The great preference of the short-dormancy variety Cangi, has denied farmers other recently released varieties, 
particularly the processing types which have longer keeping quality (Kipkoech et al., 2012). Encouraging small-scale farmers to store farm-saved seed stocks is required for farmers to keep up their own seed potato supplies for planting the following season under low-cost conditions which they can afford. The main objective of this study was to investigate the feasibility for on-farm seed potato storage of seed potatoes in selected areas in Nyandarua.

\section{Materials and Methods}

On-farm seed storage trials were conducted amongst three farmers' groups (Kagema Fukuza Njaa in Ol-Joro-Ok, Pyhort in Ol-Joro-Ok and Gatarwa Evergreen in Ol-Kalou) and three individual farmers (Miss Jane Wanjiku of Kipipiri Manunga, Hellen Wairimu of Kipipiri Githioro, and Mr. and Mrs Wairegi of Njabini) in Nyandarua County. The farmers had naturally ventilated seed storage structures with diffused light (DLS) built according to their own requirements. The stores ranged from (1) ordinary wooden store with ironsheet roof, (2) ordinary structure covered with polythene sheet; (3) mud-walled, iron-sheet roof; and (4) wooden structure with mesh wire sides and iron sheet roof.

Triplicate samples of fifteen kilogrammes of certified seed tubers of 8 varieties (Asante, Desiree, Dutch Robjin, Kenya Karibu, Kenya Mavuno, Kenya Mpya, Sherekea, and Tigoni) and Cangi, a popular unofficially recognized cultivar, were placed in wooden crates and stored for approximately 8 months for planting the following season. Three crates of each variety were stacked together to create more space in the stores. The tubers were stored for two seasons following a short rains season harvest (season 1) and a long rains season harvest (season 2). Tubers were checked periodically for sprout growth, shrinkage and rotting. Chemical control was used against tuber moth damage and aphid infestation. Any rotting tubers were periodically removed.

Determination of sprout growth, total weight loss, shrinkage and overall acceptability of tubers as seed were done at the end of storage. The seed tubers were weighed using a balance to determine total weight loss while the lengh of sprouts was measured using a ruler. Four panelists familiar with potato seed tuber quality used a 9-point scoring scale to evaluate tuber shrinkage (firmness) and overall acceptablilty of the seed. On this subjective scale a score of 1 was the least acceptable while 9 was the most acceptable; a score of 5.0 and above was acceptable.

\section{Results and Discussion}

Mean tuber growth of 8 varieties across two seasons in various on-farm sites in Nyandarua is given in Table 1.

Table 1. Mean sprout length $(\mathrm{mm})$ and standard deviation of the means of potato varieties stored for eight months over two seasons by six farmers in Nyandarua County

\begin{tabular}{lccc}
\hline Potato variety & Short rains (Season 1) & Long rains (Season 2) & Overall Mean \\
\hline Asante & $42.17 \pm 8.53^{1}$ & $52.92 \pm 25.8$ & 47.54 \\
Desiree & $39.89 \pm 22.61$ & $31.17 \pm 11.8$ & 35.53 \\
DutchRobjin & $27.33 \pm 3.88$ & $38.89 \pm 9.60$ & 33.11 \\
Kenya Karibu & $23.63 \pm 6.28$ & $68.33 \pm 34.90$ & 45.98 \\
Kenya Mpya & $32.18 \pm 10.17$ & --------- & 32.18 \\
Kenya Mavuno & $25.00 \pm 10.00$ & $41.25 \pm 11.30$ & 33.13 \\
Sherekea & $34.50 \pm 12.70$ & --------- & 34.50 \\
Tigoni & $29.58 \pm 8.76$ & $40.00 \pm 8.52$ & 34.79 \\
\hline
\end{tabular}

${ }^{1}$ Standard deviation of the mean.

Generally, variety Asante had the longest sprouts across the two seasons. Kenya Karibu had long sprouts during season 2 possibly because the long rains crop may have been harvested when not fully matured leading to early sprouting. Kenya Mavuno and Tigoni had long sprouts, but shorter than those for Asante. Early sprouting varieties can be planted 2-3 months after harvest although fully mature tubers can keep for planting much later. The farmers' cultivar Cangi broke dormancy and sprouted within a period of only 6 weeks and was discontinued from the trial. This cultivar however could be planted soon after harvest, an important trait preferred by farmers because of early crop establishment in case of decreased rainfall later in the season.

The mean tuber weight loss of 8 varieties under on-farm storage in two seasons is given in Table 2 . 
Table 2. Mean percent (\%) weight loss and standard deviations of the potato varieties stored for eight months by the 6 farmers in Nyandarua County

\begin{tabular}{llll}
\hline Potato variety & Short rains (Season 1) & Long rains (Season 2) & Overall Mean \\
\hline Asante & $33.00 \pm 24.47^{1}$ & $47.67 \pm 8.90$ & 40.34 \\
Desiree & $21.33 \pm 9.43$ & $55.83 \pm 4.04$ & 38.58 \\
Dutch Robjin & $60.44 \pm 21.72$ & $29.56 \pm 25.68$ & 45.00 \\
Kenya Karibu & $27.75 \pm 19.20$ & $63.33 \pm 5.16$ & 45.54 \\
Kenya Mpya & $26.94 \pm 6.82$ & ------------- & 26.94 \\
Kenya Mavuno & $38.22 \pm 17.13$ & $52.00 \pm 15.52$ & 45.11 \\
Sherekea & $24.67 \pm 12.62$ & -------------- & 24.67 \\
Tigoni & $22.33 \pm 8.13$ & $59.67 \pm 6.97$ & 41.00 \\
\hline
\end{tabular}

${ }^{1}$ Standard deviation of the mean.

Tuber weight loss was generally greater in the second than in the first season (Table 2). In season 2, Kenya Karibu, Tigoni, Desiree and Kenya Mavuno suffered the biggest weight loss over the 8 month storage period compared with Dutch Robjin. Probably tubers of these varieties were not fully mature during harvesting due to the long rains leading to early sprouting and hence excessive weight loss during the subsequent storage. In both seasons tubers in the lower crates had more sprout growth than those at the top that received more light. Light limits the excessive growth of white, thin sprouts while it induces growth of short, stout, coloured sprouts. Insufficient light intensity is indicated by the development of long, white sprouts which promote quick shrinkage in the tubers.

The mean overall acceptability scores of seed potato tubers following 8 months of storage for two seasons are given in Figure 1.

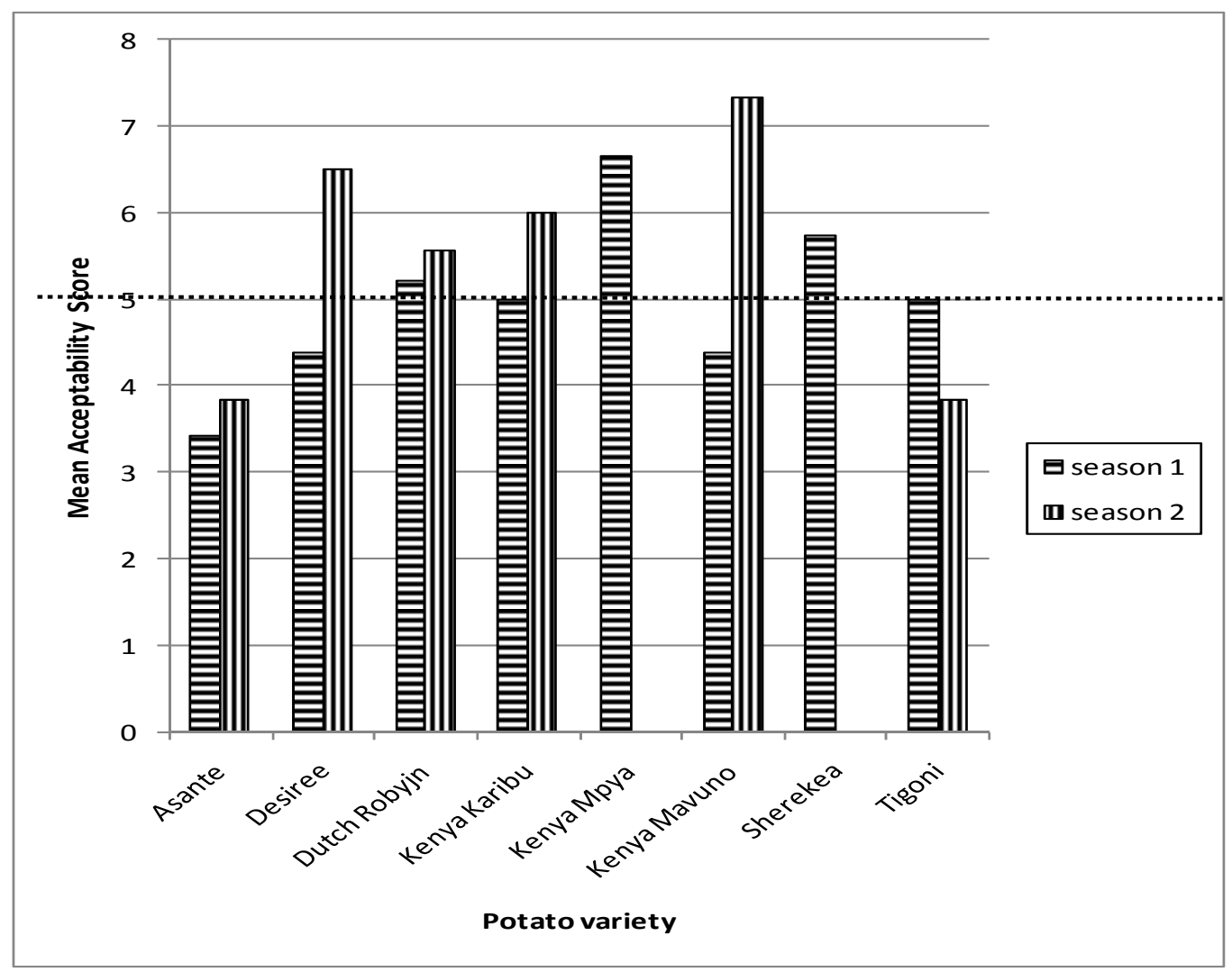

Figure 1. Mean overall acceptability scores of potato varieties after 8 months on-farm storage in Nyandarua County storage in two seasons. Scores below 5 (dotted line) were unacceptable 
There were noticeable differences in acceptability among the varieties after eight months' storage in both seasons (Figure 1). In the first season involving seed tubers harvested after the short rains season, mean panelists' scores indicated that Kenya Mavuno, Asante and Desiree were not acceptable as seed tubers probably due to excessive sprouting. Tigoni, Dutch Robjin and Kenya Karibu were just acceptable. Kenya Mpya outperformed Sherekea which also performed better than all the other varieties. In the second season, Kenya Mavuno, followed by Desiree and Kenya Karibu were the best performers. In general, tubers of most varieties had lower acceptability as seed following storage of the crop harvested in the first season (i.e short rains).

Shrinkage of seed tubers across 6 on-farm sites following 8 months of storage in two seasons is given as firmness scores in Figure 2.

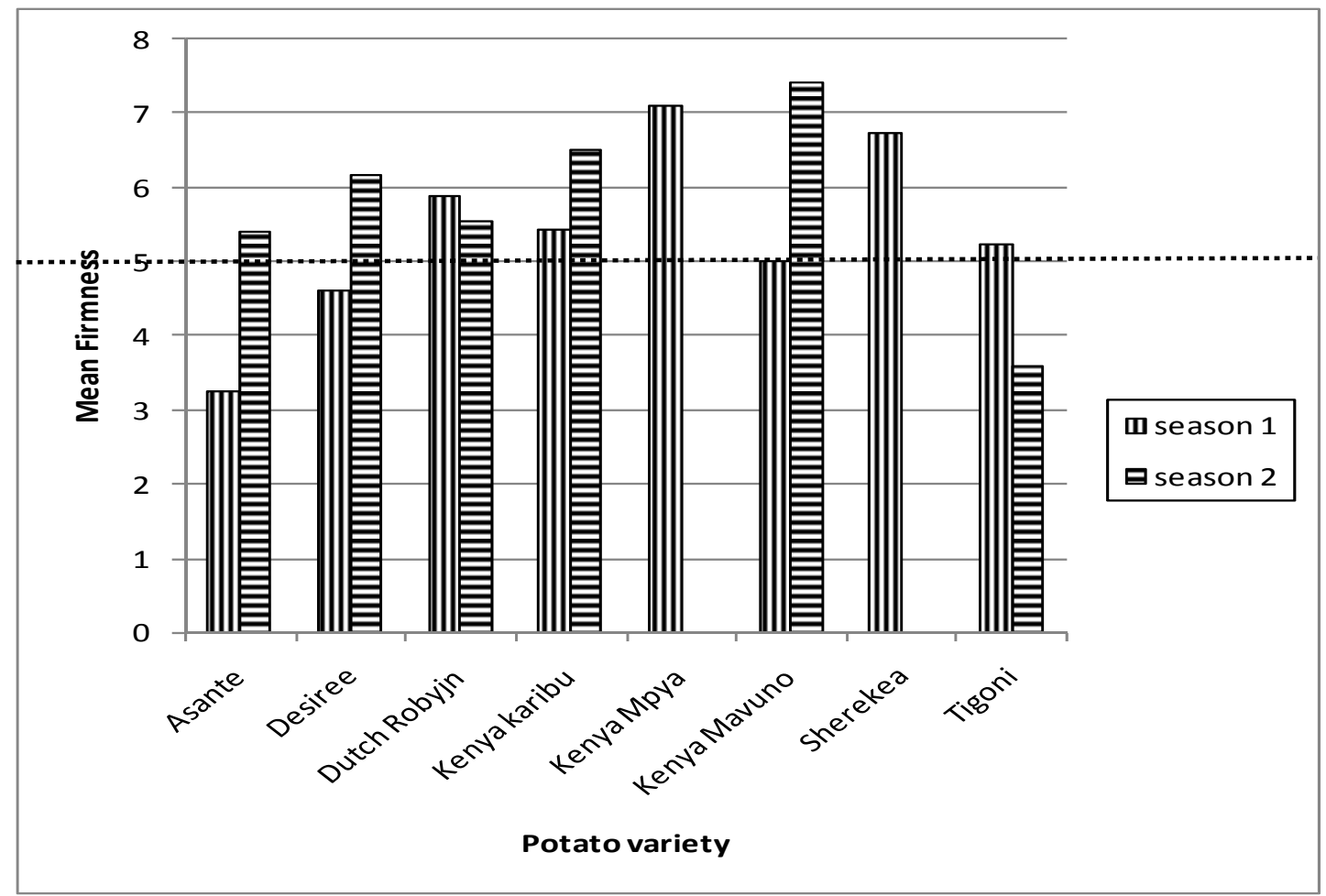

Figure 2. Mean firmness (shrinkage) scores potato varieties under on-farm storage in Nyandarua County after 8 months of storage by six farmers. Firmness scores below 5 (dotted line) were unacceptable

There were differences in seed tuber shrinkage among the varieties after eight months' storage in both seasons (Figure 2). Varieties Dutch Robjin, (5.8), Kenya Karibu (5.3), Kenya Mpya (7.1), Sherekea (6.7) and Tigoni (5.2) had firmness scores 5.0 and above during the first season. Kenya Mpya with a score above 7.0 performed the best during the first season. During the second season, all varieties except Tigoni had acceptable firmness scores. Kenya Mavuno had the highest scores.

Data on mean firmness scores of 8 varieties showing performance during storage by different farmers is given in Figure 3. All farmers had fairly good seeds of Kenya Mpya (scores of 7.0 and above) and Sherekea (6.0-7.0 scores). Tigoni and Asante had poor firmness scores in most farmers. 


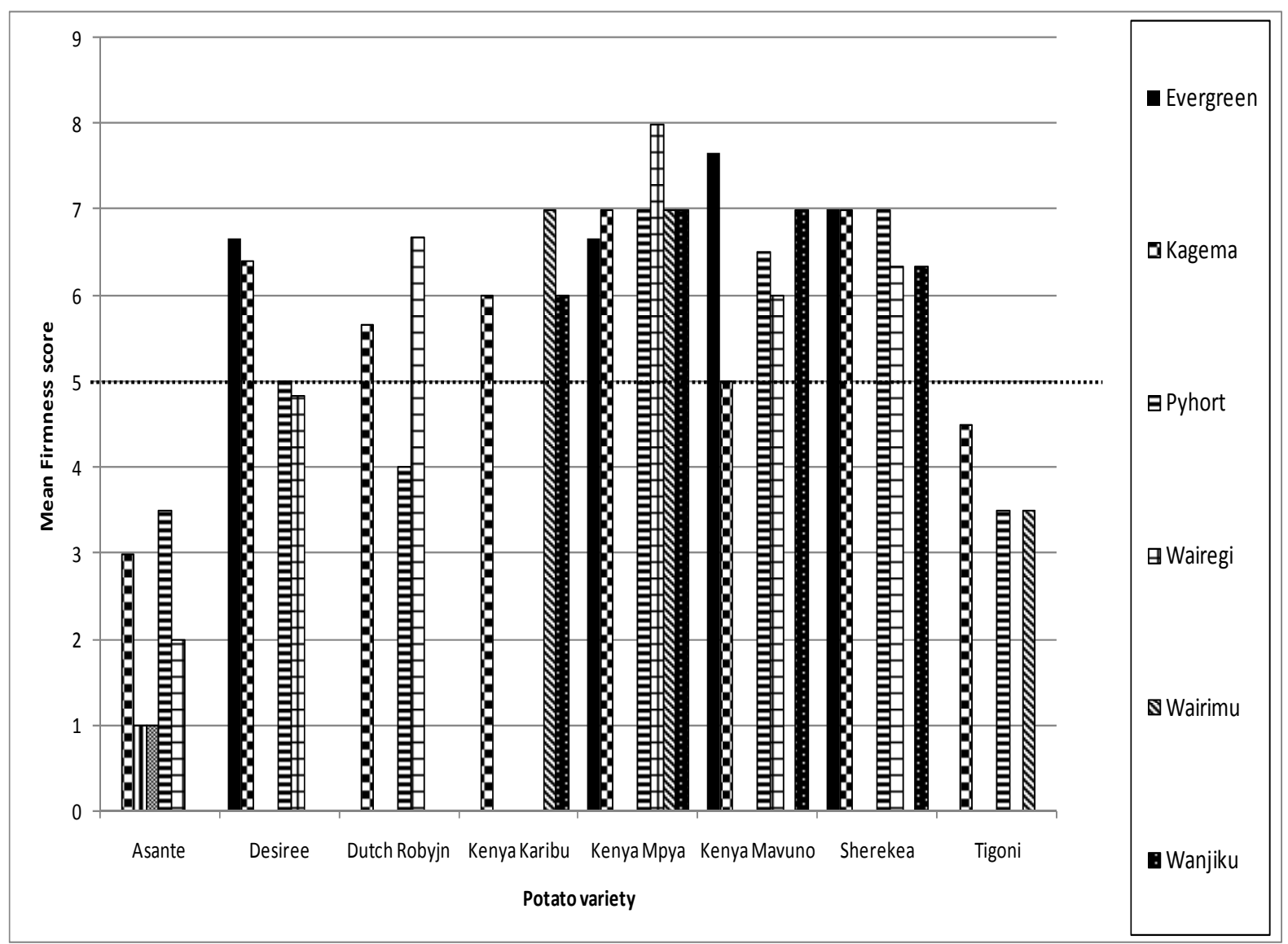

Figure 3. Mean firmness of potato varieties evaluated by six farmers for two consecutive seasons in Nyandarua County. Firmness below 5 (dotted line) was considered unacceptable

Potato varieties differed in firmness scores among sites (Figure 3). Long dormancy varieties can be stored for up to 8 months for later planting. Short dormancy varieties though not suitable for prolonged storage can supplement DLS and should be promoted as they sprout early for planting 3-4- months after harvest after harvest.

Seed tuber acceptability scores at 6 on-farm sites following 8 months of storage are shown in Figure 4. 


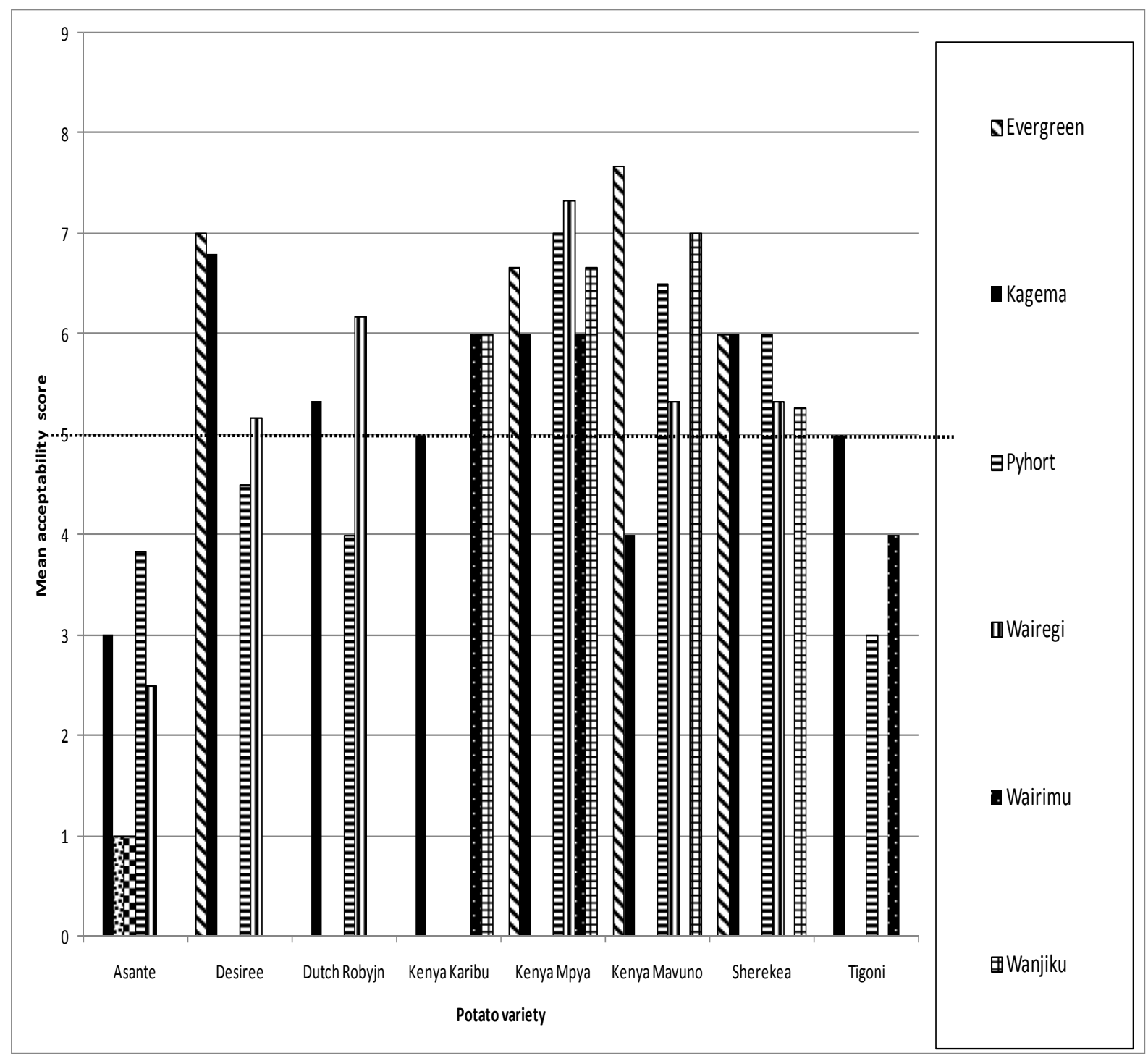

Figure 4. Seed tuber acceptability scores of potato varieties evaluated over two seasons by six farmers in Nyandarua County. Scores below 5 (dotted line) were unacceptable

Seed storage farmers did not have much effect on seed tuber acceptability scores except for stacking in crates which produced excessive sprouting in lower layers due to limited availability of light. Varieties had the most effect (Figure 1). Poor storing varieties like Asante performed poorly under all DLS while Kenya Mpya, Kenya Mavuno and Sherekea performed well.

\section{Conclusion and Recommendation}

Results of this study have shown that it is feasible to store seed tubers of currently available potato varieties in Kenya under low-cost on-farm conditions. Modification of existing storage structures to include shelves and aphid proofnetting can enhance storage of farm-saved seeds for planting the following season. Varieties selected for long storage should have long dormancy and have high market demand for domestic consumption such as Kenya Mpya or for processing such as Dutch Robjin or Desiree.

When healthy or preferably certified seed stock has been widely used for initial planting, it is ultimately possible for the Government to use protocols and standards developed by the FAO (Farjado et al., 2010) to legalize trade in farm-produced seeds to ease current shortage of planting materials. This, in conjunction with clean seed production protocols such as positive seed selection could ensure farm-produced seed can be certified for own-use for storage to ensure good seeds the folowing season. Farmers' cultivars such as Cangi having short dormancy 
periods should be officially recognized as quick sprouting could be a good characteristic to complement on-farm-storage to mitigate climate change.

\section{Acknowledgement}

The Authors are grateful to the National Council of Science and Technology for funding this work, and, Ministry of Agriculture, Mt. Kenya Univeristy and the Kenya Agricultural Research Institute for facilitating the study.

\section{References}

Fajardo, J. N., Lutaladio, N., Larinde, M., Rosell, C., Barker, I., Roca, W., \& Chujoy, E. (2010). Quality declared planting material: Protocols and stardards for vegetatively propagated crops. FAO, Rome.

Kabira, J. N., Macharia, M., Karanja, M. W., \& Murithi, L. M. (2006). Seed potatoes: How to grow and market healthy planting materials. KARI Technical Note No. 20., KARI Nairobi.

Kaguongo, W. P., Ng'ang'a, N. M., Muthoka, N., Muthami, F., \& Maingi, G. (2010). Seed potato subsectormaster plan for Kenya (2009-2014). Seed potato study sponsored by GTZ-PSDA, USAID, CIP and Government of Kenya.Ministry of Agriculture, Kenya.

Kinyae, P. M., Lung'aho, C., Njenga, D. N., \& Kabira, J. N. (1996). Adoption of potato production technologies in Nyandarua district, Kenya. Proceedings of the first socio-economic conference. KARI.

Kinyua, Z. M., Ng'ang'a, N. M., Kabira, J. N., Lungaho, C., Karinga, J., \& Kipkoech, D. (2012). Potatoes benefit farmers and other value chain players. Poster prepared to encourgae farmers to grow potatoes in areas where diseases have made maize production highly uneconomical. KARI-NARL, Kabete.

Kipkoech, D. N., Nga'ng'a, N. W., Kabira, J. N., Ooko, G. A., Nderitu, J. H. (2012). On-farm seed potato storage in Kenya: A case study of Nyandarua.Presented at the KARI Biennial Scientific Conference and Exhibition of innovations. 22-26 October 2012, KARI HQ Coplex, Kaptagat Rd, Loresho, Nairobi.

MoA. (2008). National policy on potato industry. Policy reforms to revitalize the potato industry, Ministry of Agriculture, Nairobi, Kenya.

Nyongesa, N., Kipkoech, D., \& Kinyae, P. M. (2012). Potato production in practices in four Counties (Kiambu, Nyandarua, Meru and Nakuru. Unpublished report, KARI-NPRC, Tigoni.

\section{Copyrights}

Copyright for this article is retained by the author(s), with first publication rights granted to the journal.

This is an open-access article distributed under the terms and conditions of the Creative Commons Attribution license (http://creativecommons.org/licenses/by/3.0/). 